\title{
A long association with Professor Satish Dhawan: Personal reminiscences
}

\author{
Roddam Narasimha* \\ Jawaharlal Nehru Centre for Advanced Scientific Research, Bengaluru 560 064, India
}

ON this important occasion, the birth centenary of Prof. Satish Dhawan, I cannot resist the temptation to mention some of the interesting experiences I have had over my long association with him.

\section{Dhawan and I join AE/IISc}

To begin with, looking back, I had the good fortune of joining the Department of Aeronautical Engineering of the Indian Institute of Science (IISc) for my postgraduate degree around the same time as Satish Dhawan (SD) joined the Department as an Assistant Professor. He came to India from the United States in 1951 but a selection committee which was presumably unaware of the remarkable work Dhawan had done at Caltech, USA, on important issues of the day in aerodynamics and fluid dynamics, gave him only a position of Senior Scientific Officer.

\section{There is a star on the campus}

Looking back, I entered the Department for the first year of the Diploma course the same day as Dhawan did for teaching it. I can therefore really claim that we knew each other from the beginning! I still vividly remember the first day of the term when Dhawan was starting his course on aerodynamics. He drove up in a small $\mathrm{MG}$, jumped out of the car to enter the Aeronautics Department of which the entrance was built above a $5 \mathrm{ft} \times 7 \mathrm{ft}$ wind tunnel that had been built earlier. Dhawan was wearing a coloured shirt and with a young man's agility, ran up the staircase, crossed the tunnel and ran down on the other side, opened the door to the classroom and said with a big smile on his face, 'Good morning to all of you!' The students were struck by the pleasant greetings they got from Dhawan and became conscious of a new kind of lecturer: the faculty who had joined earlier were generally all dressed in a coat and tie and usually very formal in their method of instruction. In fact, within a few days of his appearing on the campus, he became a conspicuous figure and a star on the campus. He took his teaching seriously and wanted the students to understand the fundamentals and often gave them notes, tables, fig-

\footnotetext{
*e-mail: roddam@alumni.iisc.ac.in
}

ures, etc. to make things clearer to them. Students staying in the Institute's hostels had quickly noticed that the lights would be burning in Dhawan's office as he prepared for the coming days' classes.

\section{Learning fluid dynamics}

Apart from Dhawan, who had a mastery of relatively recent developments in Aero- and Fluid-dynamics, there was another well-known figure in the Department, namely Oskar Tietjens. Both Dhawan and Tietjens were keen to make sure the students understood the fundamentals but their methods were different. Dhawan gave the course with dynamical explanations, would like to demonstrate principles through experiments because he felt that experiments make the point that could be remembered for long. Tietjens on the other hand, as a student of the renowned father of modern fluid mechanics, Ludwig Prandtl, considered it important that every student in the classroom should understand the fundamentals. And he had interesting German movies of interesting flows to show. That was more important for him than the syllabus and he would go out of his way to explain a certain result, writing on the board and explaining what it means in terms of fundamental dynamics. So, we had two different persons in the faculty who were outstanding in fluid mechanics.

In the second term, Dhawan started by teaching supersonic flows. In the 1950s, it was considered an exciting new subject in aeronautics and attracted a lot of attention in western countries. It was not yet the Space Age, but in the early 1950s the big news was about supersonic vehicles, aircraft of all various kinds that were flying at supersonic speeds. At that time, for an Indian student the word supersonic was still very strange and fashionable. Dhawan gave the second course on Supersonic Aerodynamics. He talked about how you could have bodies going above the speed of sound and considered it most important to deal with it by making an experimental demonstration. He had by then built the high-speed aerodynamics lab, and to demonstrate the supersonic flows he had already constructed a small supersonic tunnel which you could carry in one hand. That had a $1 \mathrm{~cm} \times 1 \mathrm{~cm}$ test section panel where you could put in a very small wedge with a sharp leading edge which carried shock waves. There was an air compressor in the lab and he used it to 


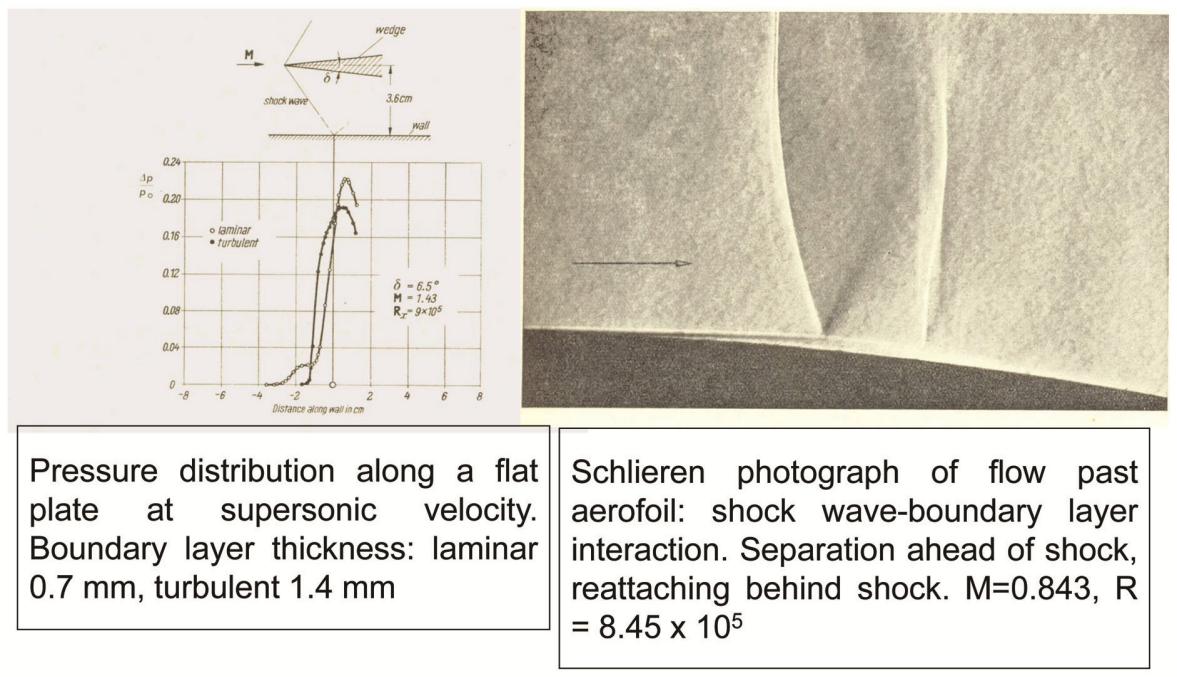

Liepmann, Roshko, Dhawan, 1951, NACA Rep 1100

Figure 1. Shock boundary layer interaction.

fill two oxygen tanks from a Dakota aircraft of second World War vintage, set the tunnel up and pushed the compressed air through the tunnel section for some fraction of a minute. He had also optical Schlieren images which could be used to show pictures where a typical supersonic shock wave could be seen and what the significance of those on the wings were. Dhawan was keen to show the students about the peculiar nature of supersonic flows containing shock waves and expansion waves (Figure 1). That was typical of Dhawan. He loved to make devices of various kinds to demonstrate what students considered strangely new, to convince them that they are the realities. That kind of demonstration made a big impression on the students.

He was busy building slightly bigger supersonic tunnels ( 1 inch $\times 3$ inch, 5 inch $\times 7$ inch), and cleverly using instruments often used by physicists to obtain fluid dynamical variables. He asked me whether I would help him in the lab and I was happy to do so as the subject was still very new. His objective in IISc was clearly to make experiments which were new but always had a specific aim of helping technology and industry. So, he would pick problems in these areas and start more work.

\section{Starting some research}

He was also interested in boundary layer research and had built a special tunnel in the boundary layer lab. This had become important in Bangalore because the data obtained from the $5 \mathrm{ft} \times 7 \mathrm{ft}$ tunnel for the HF24, a military aircraft which was then the major project at HAL needed higher levels of accuracy. The Chairman of HAL had a German engineer, Kurt Tank who was helping on the HF24. He would occasionally drop by at the Department and look at the models, and testing results, etc. Dhawan realized that it must be the turbulence in the tunnel that really determined whether or when the flow goes from laminar to turbulent, and if the turbulence was very high, the transition occurred sooner. But it could not be immediately settled, so we decided to look at the transition problem. In the light of this situation, Dhawan decided that the two of us should undertake research on transition from laminar to turbulent flow on a flat plate in the 20 inch $\times 20$ inch boundary layer tunnel. As we were planning to do this news reached us from the US that there was a new theory proposed by Emmons at Harvard that the transitional boundary layer does not occur across a jagged line separating laminar from turbulent flow; instead turbulence grows in spots which keep growing moving downstream, eventually filling the whole surface. A series of careful experiments conducted by the National Bureau of Standards confirmed the Emmons' picture. He defined intermittency at any point as the fraction of time that the flow at any given point is turbulent. However, experimental data on intermittency was not compared with the value predicted by the Emmons' theory. When the prediction of Emmons' theory was compared by me with the NBS data, the disagreement was huge. I was amazed at this result and showed it to Dhawan, and kept worrying about why this was so. Then I found out that the Emmons' theory could be inverted to determine the number of spots created per unit area in terms of the intermittency. The number so obtained corresponded to concentrated breakdown into spots at one downstream position with laminar flow upstream and intermittent flow downstream of a well-defined line of transition. By then we had made some of our own measurements and they were all in agreement with this. 
Both Dhawan and I were excited and a note was submitted to the American Journal of Aeronautical Sciences. I think he was convinced but it was characteristic of him to say 'Narasimha, let this be in your name' and struck off his name. It was immediately accepted.

I must mention that almost all the equipment needed to make these measurements were built locally in the lab. The velocities were measured using a very small hot wire probe with wire diameter of 1-2 microns and length of about $0.5 \mathrm{~mm}$. This was a tricky thing to do. Handling those thin wires was not easy and I would break one or two of them now and then. So once he called me and said 'Narasimha, look here, I will make it and you please follow me in detail'. So Dhawan made me sit next to him showing me each step of the process of making the probe saying 'Narasimha, this is like doing pooja!'. We then found out that the behaviour of the transitional flow was well predicted by our theory of intermittency. Just as we were finishing our script that we were writing for the newly established Journal of Fluid Mechanics, Kurt Freidrichs, a distinguished mathematician came to visit us. Dhawan had left him with me for some time for a discussion. So, when I described to him the spot theory and our modifications of the Emmons' theory, he was surprised. I answered all his questions for about 15 minutes, at the end of which I could no longer handle them as they were very theoretical. Dhawan asked me to write this work up for the thesis for the Associateship and read a fair bit of it as I was doing it. Then he told me 'there is not much that I can teach you, you better go to Caltech'. He wrote to Caltech and I was immediately admitted. So at the end of two years, I actually left for the US. If I had not been accepted, there was no chance of me going abroad. It sounds strange today that although I had no plans to go abroad, I landed in California.

\section{Going to Caltech}

With my AIISc, I was admitted to Caltech in 1957 to work with Hans Liepmann, who had also been advisor to Dhawan at Caltech, and left by air to Pasadena. I found that all the faculty, the students and the lab staff were keen to enquire about Dhawan and told me stories about him. For example, on a board in the office of a lab assistant there was a message of goodbye from Dhawan and a signature by him on the board which had been preserved for six years. This feeling for Dhawan was widespread among faculty, research students and the lab staff. They told me how Dhawan had stories set in the North Western Frontier Province where a man had named his camel Greta Garbo.

The week after the term started at Caltech in October 1957 turned out to be a sensational period, because on 4th October the Russians announced that they had launched their artificial satellite, Sputnik 1, which the American people and press found difficult to believe. My arrival at Caltech therefore coincided with the beginning of the Space Age. The Russians then presented information about the time at which it would appear above the horizon in the evening in all major cities. All of Caltech came out to watch the satellite and decide whether the Russians had succeeded or not. While the Americans had been incredulous at first, soon after they saw the satellite in the sky, their response became immediately strong and one of shock. It was amazing for me to see how quickly the US system, beginning with Universities and including National laboratories responded to this challenge. All of a sudden, space science became a popular word on campus. Research areas at GALCIT (Graduate Aeronautical Labs at the California Institute of Technology) expanded to cover hypersonic flows, plasma physics and rarefied gas dynamics (RGD). Liepmann (a physicist by training from Germany) set up an experiment to test how good the prevailing theories in RGD were. He made a simple theory and found the results were in reasonable agreement with experiment. We decided to choose RGD for my thesis subject and submitted my thesis in 1961. The shortage of experts in RGD was so high that a company in Los Angeles offered me a consultancy. Those four years were exciting because the work involved some theory, some mathematics and some computing.

\section{Hans Wolfgang Liepmann on Satish Dhawan}

Just a couple of years before Satish Dhawan joined him, Hans Wolfgang Liepmann (HWL) had two Indian students who came from aristocratic families, were not used to doing hard work, and who did not do well. When HWL received a suggestion from the officer in the Department about an Indian student who wanted to work with him, he was initially slightly skeptical. Nevertheless, HWL agreed to meet Satish and was immediately greatly impressed by him. Anatol Roshko, Hans and Satish formed a three-member experimental group on shock/boundarylayer problem or interaction which was a new problem at the time. They started their work very fast. This was basically his thesis. They remained great friends for half a century. It was clear to Hans that he had acquired an outstanding member. The three friends had a great time doing research and found everything they touched exciting. They worked on several problems and Satish actually designed and made a clever device to measure surface skin friction on a flat plate in a supersonic flow. This skin friction balance and the results obtained by the instrument, became a standard for further discussion.

It was common at GALCIT for faculty and students to play ping pong. Hans admits that Satish often won and would say 'see Hans, I am a crafty Asiatic'. It was clear that Dhawan had been a very popular student, and he had left messages for all the lab staff involved. Liepmann 
liked him very much indeed. He wrote an obituary for Satish that praised his many qualities.

\section{Back to Bangalore}

I won't say much more about the US. I continued research at Caltech for another year and headed back to Bangalore in 1962. In those 5 or 6 years there had been changes in IISc. In 1955, Dhawan had become head of the Aeronautics Department and in 1962, Director of IISc. As soon as I returned from the US and had come home, I decided to go see Dhawan in the Director's Office. I had a pleasant chat about his friends at Caltech and what they were doing those days. As we were chatting, the telephone rang. Dhawan picked it up. It was clear that at the other end, the speaker was Homi Bhabha. Dhawan told him 'most of the senior faculty do not think I am good for the job and that a senior professor should be the director. I have no desire about a position in which most of the professors would not accept me. So, I would request you to permit me to resign from this position.' Bhabha said that Dhawan had not applied for the position and had not shown any inclination towards it either. 'The decision to request you to be director was that of the Council. If the decision were wrong, the responsibility has to be taken by the Council - so it is our job. Please continue as Director.' In fact, the senior professors had already gone to Court and requested that a senior professor be selected as Director. Fortunately, the Court dismissed the appeal on the ground that the members of the Council had a lot of experience and were widely known in the country as wise and experienced men. After these events, Dhawan set about changing the institute that in fact needed change. There were only 11 departments, none of the modern areas was represented and the students used to say jokingly that the Institute had a large Gymkhana surrounded by small labs. As the opposition to Dhawan's directorship began to fade, Dhawan began to introduce various measures all the way from structure of the course to the method of examination. He also introduced newer areas by inviting well-known scientists to join the institute as professors who could run laboratories on the special subject as under their charge. These changes transformed the campus. Furthermore, unlike the old system, in which there was only one professor who was also heading the department, Dhawan introduced a system in which there was more democracy. The heads of Departments, he changed once every five years. Till then, the only body which represented the faculty of the institute was the Senate with only 11 professors. All of these things were quickly changing; in fact, Dhawan formed a body known as the Faculty which was made up of all faculty including Assistant Professors and discussed matters connected with courses, examinations and admissions-related issues. Around 1970-71, Dhawan probably began to feel that he was doing no research as he could not find the time and decided to go on a sabbatical to his alma mater, Caltech. He was welcomed with open arms and started doing laboratory experiments once again.

\section{A beginning in space science and technology in India}

A beginning had been made in the country in space science and technology by Vikram Sarabhai. Unfortunately, the sudden death of Vikram Sarabhai who headed the atomic energy commission and also was in charge of the space programme left a certain void. The Government of India with Mrs Indira Gandhi as Prime Minister was very keen to continue the space programme, and after discussions with others including M. G. K. Menon and the PM's principal advisor, P. N. Haksar, requested Satish Dhawan to head it. This was a hard decision for Dhawan to make. He finally decided on what he wanted to do in his own way and wrote a long letter about what ISRO should do, emphasizing in particular, solving problems of society and all people in difficulties. He also did not want to leave IISc, particularly because Bangalore was a place where many of the capabilities required in aerospace technology were more or less available compared to Ahmedabad or Delhi. He also did not want to take any major salary from the central government, and eventually had to accept one rupee for his monthly salary. He once took a bet with a junior engineer in ISRO on some point of contention, betting one month's salary: the young man won the bet and claimed his reward, only to be informed that it was one rupee since that was Dhawan's ISRO salary! Dhawan's view about science and technology even before running the space programme had been offered to him was that IISc must select technology problems for which industry has no solution. He also insisted that the major objective of ISRO should be to serve society as much as possible. Indira Gandhi had at first almost insisted that the development of technology in India should be connected with defense and security matters. Jairam Ramesh, author of a recent book (Intertwined Lives, 2018 , p. 243) talks about how this problem was solved.

\section{The value of science for human society and humane people}

This is a particularly Indian virtue. It was introduced first by IISc. Dhawan was deeply concerned to find solutions to the natural problems in India through the use of science and technology. I did have an opportunity to help him in some of these areas. For example, through Astra (Cell for the Application of Science and Technology for Rural Areas), the idea of A. K. N. Reddy, I did my little bit to set up a savonious rotor at a village called Ungra for which Astra was in charge. This finally led to the 
establishment of the Karnataka State Council for Science and Technology, which has become an organization with definite objectives and has many universities and colleges across the whole State of Karnataka in research, development of technology and education.

In Bangalore, and in certain rural areas away from Bangalore, ISRO had started an impressive move. For example, when ISRO took over Sriharikota there was a tribe living there for a long time. Dhawan went out of his way to make them comfortable. He built small new houses for them whenever possible and gave them jobs in ISRO and provided education facilities for their children. He created a little museum on the campus to display the art work of the local people. All of this made the atmosphere there very peaceful.

Bangalore had a small group of some well-known people including A. R. Vasudeva Murthy (Professor of Chemistry, IISc), M. A. Sethu Rao (Professor of Chemistry at Central College, Bangalore), D. D. Kosambi, a well-known mathematician who worked at TIFR, Bombay and J. R. Laxman Rao, who would all get together at IISc at certain intervals to monitor how these projects were progressing. It is interesting that two Sanskrit scholars Kosambi and Vasudeva Murthy approved of such social initiatives.

At a family level I once had the opportunity to be taken by Dhawan to his sister's house. He was two years short of retirement at IISc and therefore said he was looking to build a 'hut' for himself. In earlier discussions with his friends, he had said, he would need 20 lakhs for the 'hut'. So, he asked his sister 'can you get 20 lakhs for the house that our father left us?' His sister laughed out loud and said 'Satish, you are not in touch with the real world. You have a house that is worth close to 50 lakhs'. Satish said, 'I really only need 20 lakhs'. I don't know how they settled it eventually but it was an excellent example of the value for money that Dhawan had.

\section{Building the ISRO 'culture'}

For decades now, the concept of ISRO having a special culture of its own has been widely accepted not only by its proud employees but also by the general public. This 'culture' has several aspects. First of all, a very efficient and committed employee is treated gently and generously by ISRO leaders. I remember a technical review project of SLV-3. All engineers who had any contribution to make were invited to the review auditorium. The leader of the project namely A. P. J. Kalam had responded to a particular question by a person who was at the back of the auditorium. Kalam as usual was very polite and responsive, but his answer to person at the back of the house was not sufficiently clear. Dhawan who was sitting in front said loudly 'Kalam, everybody has the right to get a proper answer to a valid question. Please answer it'. Kalam seemingly embarrassed gave the proper answer. Dhawan's objective in demanding a proper answer was that he wanted every qualified engineer at the conference to be in a position to know the design parameters of any vehicle that had been approved. He was also very keen that in a technical discussion, the engineers were all equal no matter what their positions were.

Many of Dhawan's demonstrated actions show again and again that he believed in Indian talent. Several illustrations of this can be given. His methods of management and his sense for humanity and impartiality with employees gave a sense of confidence in the management that was rather unusual in India for a public sector organization. It slowly turned out to be understood that Dhawan had over the years created that culture, which had grown and was accepted widely by virtually all of its employees and gave them a certain pride of being space scientists and engineers. This confidence was recently made very clear in a survey made in Bangalore by an international company, of the companies that young scientists and engineers would like to work in, in particular multinational companies. Among a host of such companies, ISRO was number 5. The only other Indian organization in that list at number 15 was the Tata Consultancy Services. ISRO's salary is government salary, and it was clear that the young people were not just longing for money, but were looking for challenges and for achievement and to be able to play a key role.

With my association over decades, I consider Dhawan to have been a remarkably unique person - a true scientist and a silent socialist. I mean by this that he never spoke loudly about socialism but he took action that was consistent with the principles of socialism. He provided the best possible facilities for the poorer sections of society. He spent his time trying to do the best for the country and so I consider him a real patriot. In spite of his enormous responsibilities in ISRO and IISc, he never gave up being a true scientist. During his later years, he got very interested in bird flight, especially of those birds living near Sriharikota and wrote a widely read book, Bird Flight. As I was leaving Pasadena for Bangalore in 1962, China and India were at war. Dhawan's guru HWL said, 'if you have ten Dhawans in your country, all your problems will be solved'.

ACKNOWLEDGEMENTS. In the writing of this article, I have received great help from Miss. K. Nagarathna. I have also had many useful and interesting conversations with Prof. Jyotsna Dhawan.

doi: $10.18520 / \mathrm{cs} / \mathrm{v} 119 / \mathrm{i} / 1422-1426$ 